\title{
Research on design value of compressive strength for Chinese fir dimension lumber based on full-size testing
}

\author{
Yingchun Gong ${ }^{1}$ - Guofang $\mathrm{Wu}^{1} \cdot$ Xiuqin Luo ${ }^{1}$ Zhaohui Wang ${ }^{1} \cdot$ \\ Jinghui Jiang ${ }^{1} \cdot$ Haiqing $\operatorname{Ren}^{2}$
}

Received: 29 July 2016/ Accepted: 15 October 2016/Published online: 25 November 2016

(C) The Japan Wood Research Society 2016

\begin{abstract}
The objective of this study was to obtain design value, which was calculated according to the limit states design method, for the utilization of Chinese fir in the building structure field as a green building material. A total of 342 specimens were tested by static compression method. The normal and lognormal distributions were selected to fit the experimental data. The results indicated that reliability index increased nonlinearly with the live-todead ratio and resistance partial coefficient increased. To meet the target index $\left(\beta_{0}=3.2\right)$, it was suggested that design values of compressive strength of Chinese fir were set to $13.751,13.186$, and $13.123 \mathrm{MPa}$ for SS, No. 1, and No. 2 grade, respectively.
\end{abstract}

Keywords Design value $\cdot$ Chinese fir - Compressive strength $\cdot$ Limit states design method

\section{Introduction}

With the rapid development of the wooden structure in China, the demand for wood resources has been increasing in recent years. However, due to enforcing logging-ban at the natural forest effective in 2015 in China, wood nature resources is in serious shortage. Therefore, plantation resources need to be developed and

Haiqing Ren

renhq@caf.ac.cn

1 Research Institute of Wood Industry, Chinese Academy of Forestry, Beijing 100091, People's Republic of China

2 Research Institute of Forestry New Technology, Chinese Academy of Forestry, Beijing 100091, People's Republic of China utilized in China. Chinese fir (Cunninghamia lanceolata) is one of the three main plantation tree species in China. It distributes from latitude $22-34^{\circ} \mathrm{N}$ and longitude $100-122^{\circ} \mathrm{E}$. Chinese eighth national forest resources survey shows that the area of plantation of Chinese fir is 9.21 million ha $[1,2]$. In the meantime, Chinese fir has many advantages, such as fast-growing, good mechanical performance, and decay resistance. It has been widely used to fabricate dimension lumber, glued lumber, and wood-based composites [3, 4]. However, due to the lack of design values of mechanical properties for engineered wood products, thus it is unsafe to use these in the building structure filed.

Dimension lumber has standardized design dimensions. It has been used in a variety of applications including in building frame, floor, and wall components $[5,6]$. The visual grading and machine stress rated methods were applied to evaluate the strength grading of dimension lumber. According to National Lumber Grades Authority (NLGA)-Standard Grading Rules for Canadian Lumber [7], the visual grading divided lumber into four grade including SS, No. 1, No. 2, and No. 3, based on wood growth characteristics. It lines up with the classification in Chinese National Code [8] including Ic, IIc, IIIc, and IVc grade.

There are significant differences on the design value of mechanical properties for the same grade dimension lumber, because different countries have different evaluation methods, load statistics, and load combinations. For example, the statistics of snow load $(q)$, which equals the ratio average value and standard value, is 1.04 in China, but $q$ value ranges from 0.61 to 0.82 in the United States [9]. Furthermore, design value of wood strength is generally determined by full-size testing and small clear specimens testing [10]. Comparing these two methods, the full-size 
testing takes natural defect, size effect, and other factors into consideration. Therefore, the test results are much closer to the actual situation. The previous research [11] reported that the length had significant effect on tensile strength of visually graded Chinese fir dimension lumber. Currently,the full-size testing method has been applied in the United States, Canada, and Japan to determine the flexural, compressive, and tensile strength of dimension lumber $[12,13]$. However, according to Code for design of timber structures [8], the design value is still based on small clear specimens testing for dimension lumber fabricated with native tree species.

In this study, a total of 342 specimens were tested by static compressive method. The object was to determine design values of full-size compression strength parallel to grain (UCS) for Chinese fir dimension lumber based on the first-order second-moment reliability analysis. The research on design value will provide basic data for the application of Chinese fir in the building structures filed.

\section{Materials and methods}

\section{Materials}

To ensure random and representative of samples, Chinese fir (Cunninghamia lanceolata) was harvested from Huangshan mountain forest farm of Anhui Province, Xuefeng mountain forest farm of Hunan Province, and Helong forest farm of Sichuan Province, China. In total, 80 $\operatorname{logs}$ with $3 \mathrm{~m}$ long and the diameter at breast heights samples were divided into SS, No. 1, and No. 2 grade. Two compression samples with dimensions $40 \times 90 \times 350 \mathrm{~mm}$ for UCS testing were cut from the normal dimension lumbers of Chinese Fir, and one of them contained the maximum strength-reduced defect. Sample size for each grade is shown in Table 1.

\section{Static test methods}

The compressive tests were performed in accordance with ASTM D4761-2009 [14]. The required failure time was between 3 and $10 \mathrm{~min}$. To accommodate the time to failure requirement, loading speed was adjusted to $2 \mathrm{~mm} / \mathrm{min}$. The specimens were tested using a universal machine (INSTRON 5582) and the maximum load was recorded as the failure load. All specimens were conditioned at $20{ }^{\circ} \mathrm{C}$ and at $65 \%$ relative humidity (RH). Weight, dimensions, and moisture content of each specimen were measured after the equilibrium moisture content reached. The compressive strength of Chinese Fir dimension lumber was calculated using Eq. 1.

$$
\sigma=\frac{F_{\max }}{b t},
$$

where $\sigma$ is the compressive strength, $F_{\max }$ is the maximum compressive strength applied to the specimens during the test $(\mathrm{N}), b$ is the width of the specimens $(\mathrm{mm})$, and $t$ is the thickness of the specimens $(\mathrm{mm})$.

The UCS for each specimen, adjusted to $15 \%$ moisture content $\left(\mathrm{UCS}_{15}\right)$ in accordance with ASTM D1990-2007 [13], can be calculated by the following equation:

$\mathrm{UCS} \leq 9.66 \mathrm{MPa}$

$\mathrm{UCS}>9.66 \mathrm{MPa}$ ranged from 250 to $320 \mathrm{~mm}$ were selected. The logs were cut into dimension lumber using four sawing method. Due to measure in millimeters $(\mathrm{mm})$ using in Chinese Code, sizes of the $40 \mathrm{~mm} \times 90 \mathrm{~mm}$ were deemed identical to $2 \times 4$ of North American commercial lumber sizes. The length of dimension lumber was $2550 \mathrm{~mm}$. The samples were graded by visual grading according to NLGA. The

Table 1 Sample size of each grade

\begin{tabular}{lc}
\hline Grade & Sample size \\
\hline SS & 136 \\
No. 1 & 98 \\
No. 2 & 108 \\
\hline
\end{tabular}

where $M_{1}$ is the moisture content of the specimen (\%).

\section{Probability distribution}

The normal and lognormal distributions are generally adopted as parametric statistical model in the analysis of mechanical properties. The probability density function

$f(x)$ and cumulative distribution function of standard normal distribution $\phi(x)$ can be expressed as follows:

1. Normal distribution

$$
f(x)=\frac{1}{\sqrt{2 \pi \sigma}} \exp \left\{-\frac{(x-\mu)^{2}}{2 \sigma^{2}}\right\} \text {, }
$$


$\phi\left(\frac{x-\mu}{\sigma}\right)=p$

where $x$ is the random variable, $\mu$ and $\sigma$ are mean and standard deviation, respectively. $p$ is percentile value of cumulative distribution function.

2. Lognormal distribution

$f(x)=\frac{1}{x s \sqrt{2 \pi}} \exp \left\{-\frac{(\ln x-M)^{2}}{2 S^{2}}\right\}$,

$\phi\left(\frac{x-M}{S}\right)=p$,

where $M$ is the mean value of $\log$ arithm of $x$, and $S$ is the standard deviation of In $x$.

\section{Kolmogorov-Smirnov test}

The Kolmogorov-Smirnov test (K-S test) can be used to verify fitting optimization of distribution curve [15]. The formula can be expressed as follows:

$D=\max (|\phi(x)-s(x)|)$,

where $\phi(x)$ and $s(x)$ represent the cumulative probability value and theoretical distribution value, respectively. $D$ is the maximum absolute difference between $\phi(x)$ and $s(x)$.

At the 0.05 level of significance,the $D_{0.05}$ is equal to $1.36 / \sqrt{n}$ and $n$ is the number of samples. If $D$ is smaller than $D_{0.05}$, the theoretical distribution $s(x)$ can provide a good fit to the cumulative probability value $\phi(x)$ obtained by the static testing. If $D$ is larger than $D_{0.05}$, the theoretical fitting distribution $s(x)$ failed.

\section{Results and discussion}

\section{Results of compressive test}

The mean value, standard deviation, and coefficient of variance of compressive strength adjusted to $15 \%$ moisture content for Chinese Fir dimension lumber were shown in Table 2. The mean values of $\mathrm{UCS}_{15}$ for SS, No. 1, and No. 2 grade were $30.71,28.38$, and $29.37 \mathrm{MPa}$, respectively. And the mean value of $\mathrm{UCS}_{15}$ for No. 1 grade was lower than the
SS and No. 2 grade. It is due to the great influence of knots on wood strength. Besides, No. 1 grade lumber contained more knots [16]. In addition, the wane and skips in No. 2 grade had no significant effect on the wood strength [17]. The coefficient of variance $(\mathrm{COV})$ of $\mathrm{UCS}_{15}$ for SS, No. 1, and No. 2 grade were $15.90,13.55$, and $15.70 \%$, respectively. The COV for strength was mainly affected by size, defect, and species. Previous research reported that the COV of dimension lumber ranged from 10.70 to $36.70 \%$ [18]. Thus, comparison of $\mathrm{COV}$ obtained in this study to those publications shows that the characteristic of large variability for wood could be reflected by the test data.

Difference between measurement data of each grade was conducted through analysis of variance (ANOVA). The results showed that the $\mathrm{UCS}_{15}$ values showed the highly significant differences between each grade of dimension lumber $(P<0.05$, at the significance level of 0.05$)$. Therefore, the NLGA visual grading method is an adequate method to divide the $\mathrm{UCS}_{15}$ for Chinese fir dimension lumber.

\section{Probability distribution}

It is important to determine the probability distribution of mechanical strength of dimension lumber for its utilization in building structures filed. Histogram, the normal and lognormal distributions curves of $\mathrm{UCS}_{15}$ for each grade were shown in Fig. 1. The basic fitted parameters were important to determine the characteristic values, and the values of fitted parameters for two models were shown in Table 2.

$\mathrm{K}-\mathrm{S}$ test was performed using SPSS Statistics software and the results are listed in Table 3. Different sample size had different critical $D$ values. Table 3 indicated that all $D$ values of $\mathrm{UCS}_{15}$ for each grade were less than the critical $D$ values. It proved that the normal and lognormal distributions were judged to be good fit for the actual distribution of $\mathrm{UCS}_{15}$ for Chinese Fir dimension lumber. Smaller $D$ value indicates better fitting, the $D$ value of lognormal distribution for SS grade is less than that of normal distribution. Therefore, the lognormal distribution fitted the $\mathrm{UCS}_{15}$ data for SS grade seems to be better than normal distribution. In contrast, normal distribution fitted No. 1 and No. 2 grade better than lognormal distribution. To
Table 2 The compression strength adjusted to $15 \%$ moisture content for Chinese Fir dimension lumber

\begin{tabular}{|c|c|c|c|c|c|c|}
\hline \multirow[t]{2}{*}{ Statistical parameters } & \multicolumn{3}{|c|}{$\mathrm{UCS}_{15}$} & \multicolumn{3}{|c|}{$\operatorname{In}\left(\mathrm{UCS}_{15}\right)$} \\
\hline & SS & No. 1 & No. 2 & SS & No. 1 & No. 2 \\
\hline Mean value (MPa) & 30.71 & 28.38 & 29.37 & 3.41 & 3.28 & 3.30 \\
\hline Standard deviation (MPa) & 4.88 & 3.84 & 4.61 & 0.16 & 0.11 & 0.14 \\
\hline $\operatorname{COV}(\%)$ & 15.90 & 13.55 & 15.70 & 4.70 & 3.35 & 4.24 \\
\hline
\end{tabular}

$U_{C S_{15}}$ compressive strength adjusted to $15 \%$ moisture content, In $\left(U C S_{15}\right)$ logarithm of compressive strength adjusted to $15 \%$ moisture content, $C O V$ coefficient of variance 

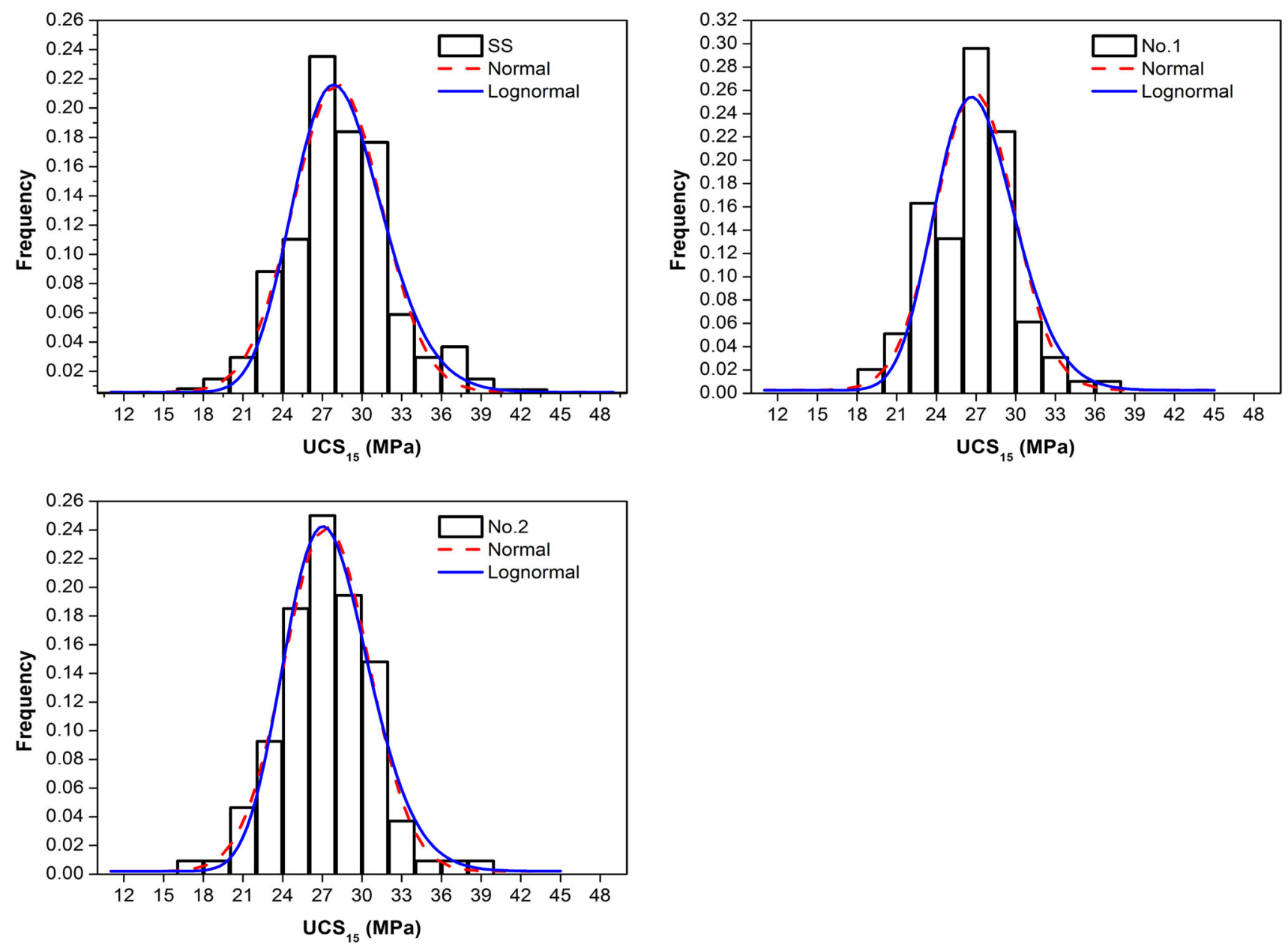

Fig. 1 Lognormal and normal fit of $\mathrm{UCS}_{15}$ for Chinese Fir dimension lumber

Table 3 Results of compressive strength using K-S method

\begin{tabular}{llll}
\hline Distribution & \multicolumn{2}{l}{ K-S test $(D$ value $)$} & No. 2 \\
\cline { 2 - 4 } & SS & No. 1 & 0.063 \\
\hline Normal & 0.081 & 0.070 & 0.071 \\
Lognormal & 0.052 & 0.086 & 0.131 \\
Critical value & 0.117 & 0.137 & \\
\hline
\end{tabular}

$\mathrm{K}-\mathrm{S}$ is the Kolmogorov-Smirnov test. $D$ value is the maximum absolute difference between the cumulative probability value and theoretical distribution value

assess the strength index more safely, both the normal and lognormal distribution of $\mathrm{UCS}_{15}$ for Chinese fir dimension lumber were selected to calculate the characteristic values in this study.

\section{Characteristic values}

According to the Chinese national standards GB 500682001 [19] and ASTM D 2915-2010 [20], the characteristic values of $\mathrm{UCS}_{15}$ for Chinese Fir dimension lumber could be estimated at $5 \%$ percentile with $75 \%$ confidence. As a lognormal distribution, the calculated characteristic values can be calculated by the following equation:

$f=e^{\mu_{f}\left(1-k \delta_{f}\right)}$,

where $\mu_{f}$ is the mean value of logarithmic $\mathrm{UCS}_{15}$ for SS, No. 1 , and No. 2 grade, $\delta_{f}$ is the COV of logarithmic $\mathrm{UCS}_{15}$ (Table 2). $k$ is a confidence level factor. Different standards and samples have different $k$ values $(k=1.645$ in Chinese national standards GB 50068-2001 [19] for all grades and $k=1.739$ for SS grade; $k=1.758$ for No. 1 and No. 2 grade in ASTM D 2915-2010 [20] at 5\% percentile with $75 \%$ confidence).

As a normal distribution, the calculated characteristic values can be expressed as follows:

$f=\mu_{f}-k s$,

where $\mu_{f}$ is the mean value of $\mathrm{UCS}_{15}$ for SS, No. 1 , and No. 2 grade; $s$ is the standard deviation of $\mathrm{UCS}_{15}$ for each grade (Table 2). The characteristic values of $\mathrm{UCS}_{15}$ for SS, No. 1 , and No. 2 grade were shown in Table 4. 
Table 4 The characteristic values of $\mathrm{UCS}_{15}$ according to different standards and distributions

\begin{tabular}{lllll}
\hline Distribution & $\begin{array}{l}\text { Characteristic } \\
\text { values }\end{array}$ & \multicolumn{4}{l}{$\mathrm{UCS}_{15}(\mathrm{MPa})$} \\
\cline { 3 - 5 } & & $\mathrm{SS}$ & No. 1 & No. 2 \\
\hline \multirow{2}{*}{ Lognormal } & $f_{1}$ & 23.25 & 22.18 & 21.54 \\
& $f_{2}$ & 22.90 & 21.90 & 21.20 \\
\multirow{2}{*}{ Normal } & $f_{3}$ & 22.67 & 22.05 & 21.78 \\
& $f_{4}$ & 22.12 & 21.62 & 21.26 \\
\hline
\end{tabular}

$f_{1}$ and $f_{2}$ represent the calculated characteristic values using the Chinese national standards GB50068-2001 [19] and ASTM D29152010 [20], respectively, corresponding with lognormal distributions. $f_{3}$ and $f_{4}$ represent the calculated characteristic values using the Chinese national standards GB50068-2001 [19] and ASTM D29152010 [20], respectively, corresponding with normal distributions

Table 4 indicated that the calculated characteristic value for SS grade was the highest. There were no significant differences for the characteristic values of $\mathrm{UCS}_{15}$ calculated according to the GB 50068-2001 [19] and ASTM D2915-2010 [20]. It is because confidence level factor $k$ value is not significantly different between GB 50068-2001 [19] and ASTM D2915-2010 [20]. Meanwhile, according to the Chinese National Standards, the calculated characteristic values of $\mathrm{UCS}_{15}\left(f_{3}\right)$ were $22.67,22.05$, and 21.78 MPa for SS, No. 1, and No. 2 grade, respectively, corresponding with the normal distribution, which were less than those of lognormal distribution $\left(f_{1}\right)$. From the structure security concerns, the calculated characteristic values of $\mathrm{UCS}_{15}$ using Chinese National Code $\left(f_{3}\right)$ were selected to calculate the design values.

\section{Design values}

The design value $\left(f_{d}\right)$ of $\mathrm{UCS}_{15}$ for Chinese fir dimension lumber based on the full-size testing and the reliability analysis is calculated using Eq. 10. The mean value $\left(\mu_{R}\right)$ and coefficient of variance $\left(\delta_{R}\right)$ of the resistance stress $(R)$ can be calculated using Eqs. 11 and 12 .

$f_{d}=\frac{\mu_{k 3} f_{3}}{\gamma_{R}}$,

$\mu_{R}=\mu_{k 1} \times \mu_{k 2} \times \mu_{k 3} \times \mu_{f}$,

$\delta_{R}=\sqrt{\delta_{k 1}^{2}+\delta_{k 2}^{2}+\delta_{k 3}^{2}+\delta_{f}^{2}}$

where $f_{3}$ is the characteristic values (Table 4). $\mu_{f}$ is the mean value of $\mathrm{UCS}_{15}$ and $\delta_{f}$ is the coefficient of variance of $\mathrm{UCS}_{15}$ (Table 2). $\gamma_{R}$ is the resistance partial coefficient. $k_{l}$, $k_{2}$, and $k_{3}$ are adjusting factors for the equation precision, geometric character, and the effect of duration of load, respectively. The statistical parameters of the adjusting
Table 5 Statistical parameters of the adjusting factors (GB 50005-2003 [8])

\begin{tabular}{lllr}
\hline Parameters & $k_{1}$ & $k_{2}$ & $k_{3}$ \\
\hline Mean value & 1.00 & 0.96 & 0.72 \\
COV $(\%)$ & 5.00 & 6.00 & 12.00 \\
\hline
\end{tabular}

$k_{1}, k_{2}$, and $k_{3}$ are adjusting factors for the equation precision, geometric character, and the effect of duration of load, respectively

$\mathrm{COV}$ coefficient of variance

Table 6 Statistical parameters of resistance stress $(R)$ for each grade dimension lumber

\begin{tabular}{lrrr}
\hline Statistical parameters & \multicolumn{3}{c}{ Resistance stress $(R)$} \\
\cline { 2 - 4 } & \multicolumn{1}{c}{ SS } & No. 1 & No. 2 \\
\hline Mean value (MPa) & 21.23 & 19.62 & 20.30 \\
Standard deviation (MPa) & 4.54 & 3.87 & 4.40 \\
COV (\%) & 21.40 & 19.71 & 21.25 \\
\hline
\end{tabular}

$\mathrm{COV}$ coefficient of variance

factors according to literature [8] are shown in Table 5. According to statistical theory, the $R$ value of dimension lumber with different grades is also in line with the normal distribution. The mean value and COV of $R$ are shown in Table 6.

To obtain the resistance partial coefficient, the limit state design equation and performance function are established based on first-order second-moment reliability analysis [19]. The limit states design method can aim to satisfy the criteria of a target safety level. The reliability evaluation of the design values can provide the reference for the future strength values updating of the dimension lumber in the Chinese standard [9]. The limit state design equation is expressed as follows:

$\gamma_{0}\left[\gamma_{D} E(D)_{n}+\psi_{C} \gamma_{L} E(L)_{n}\right] \leq f_{d}$

where $\gamma_{0}$ is the structure importance coefficients and equals to 1.0 for design life of 50 years. $\gamma_{D}$ is the dead load effect factor and equals to 1.2. $\gamma_{L}$ is the live loads effect factor and equals to 1.4. $\psi_{c}$ is the combination factor for the live load and equals to 1.0. $E(D)_{n}$ is the nominal dead load effects. $E(L)_{n}$ is the nominal live load effects. Therefore, the Eq. 13 can be written $1.2 E(D)_{n}+1.4 E(L)_{n} \leq f_{d}$.

The performance function $(G)$ is expressed as follows:

$G=g(R, S)=R-S=R-[E(D)+E(L)]$,

where $E(D)$ is the dead loads effects (random variable), which includes the self-weight of structural members and other materials. $E(L)$ is the live loads effects (random variable), which includes the office occupancy load $\left(L_{O}\right)$, residential occupancy load $\left(L_{R}\right)$, wind load $\left(L_{W}\right)$, and snow 
Table 7 Statistical parameters of the loads (GB 50009-2012 [21])

\begin{tabular}{llllll}
\hline Statistical parameters & \multicolumn{2}{l}{ Load types } & & & \\
\cline { 2 - 6 } & $G$ & $L_{O}$ & $L_{R}$ & $L_{W}$ & $L_{S}$ \\
\hline Mean/nominal & 1.060 & 0.524 & 0.644 & 1.000 & 1.040 \\
COV (\%) & 7.0 & 28.8 & 23.3 & 19.0 & 22.0 \\
Distribution types & Normal & Extreme-I & Extreme-I & Extreme-I & Extreme-I
\end{tabular}

$G$ dead load, which includes the self-weight of structural members and other materials, $L_{O}$ office occupancy load, $L_{R}$ residential occupancy load, $L_{W}$ wind load, $L_{S}$ snow load, $C O V$ coefficient of variance
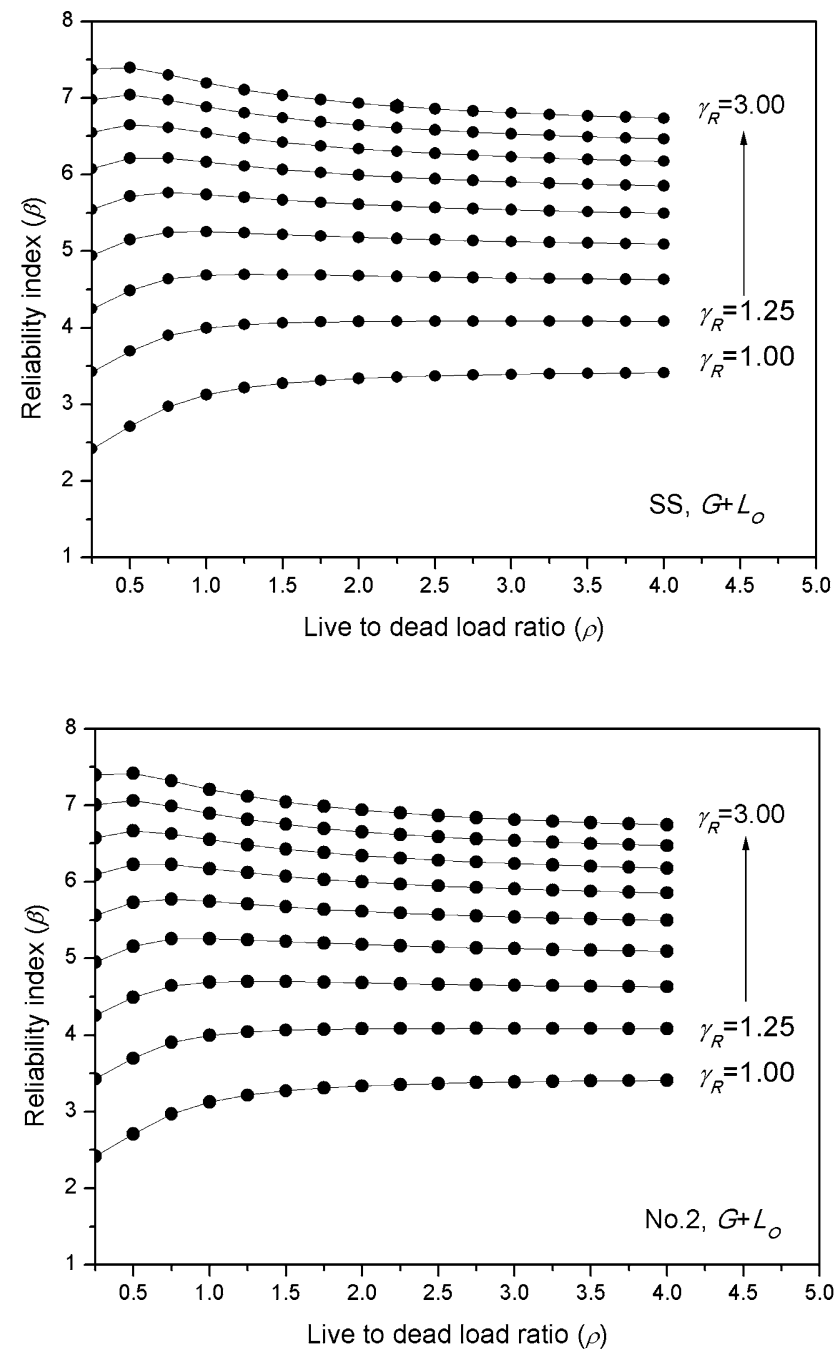

Fig. 2 Relationship between reliability index and live-to-dead ratio

load $\left(L_{S}\right)$. According to Chinese National Standard GB50009-2012 [21], the data of dead loads are in line with the normal distribution, and the data of different live loads are fitted to the extreme type-I distribution. The statistical parameters of the dead and live loads are shown in Table 7.

Combined with Eqs. 11, 13, and 14, the performance function can be expressed as follows:

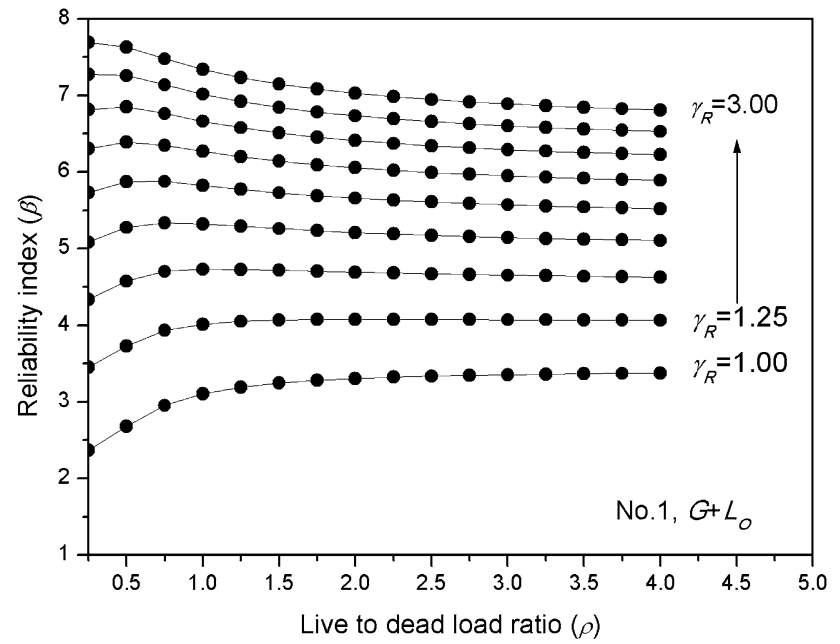

$$
\begin{aligned}
G & =R-\frac{\mu_{k 3} f_{3}[E(D)+E(L)]}{\gamma_{R} \gamma_{0}\left[\gamma_{D} E(D)_{n}+\psi_{C} \gamma_{L} E(L)_{n}\right]} \\
& =R-\frac{f_{d}(g+q \rho)}{(1.2-1.4 \rho)},
\end{aligned}
$$

where $g$ is the ratio of live load to nominal live load $(E(L) /$ $\left.E(L)_{n}\right) . q$ is the ratio of dead load to nominal dead loa$\mathrm{d}\left(E(D) / E(D)_{n}\right) . \rho$ is the load ratio $E(D)_{n} / E(L)_{n}$. 

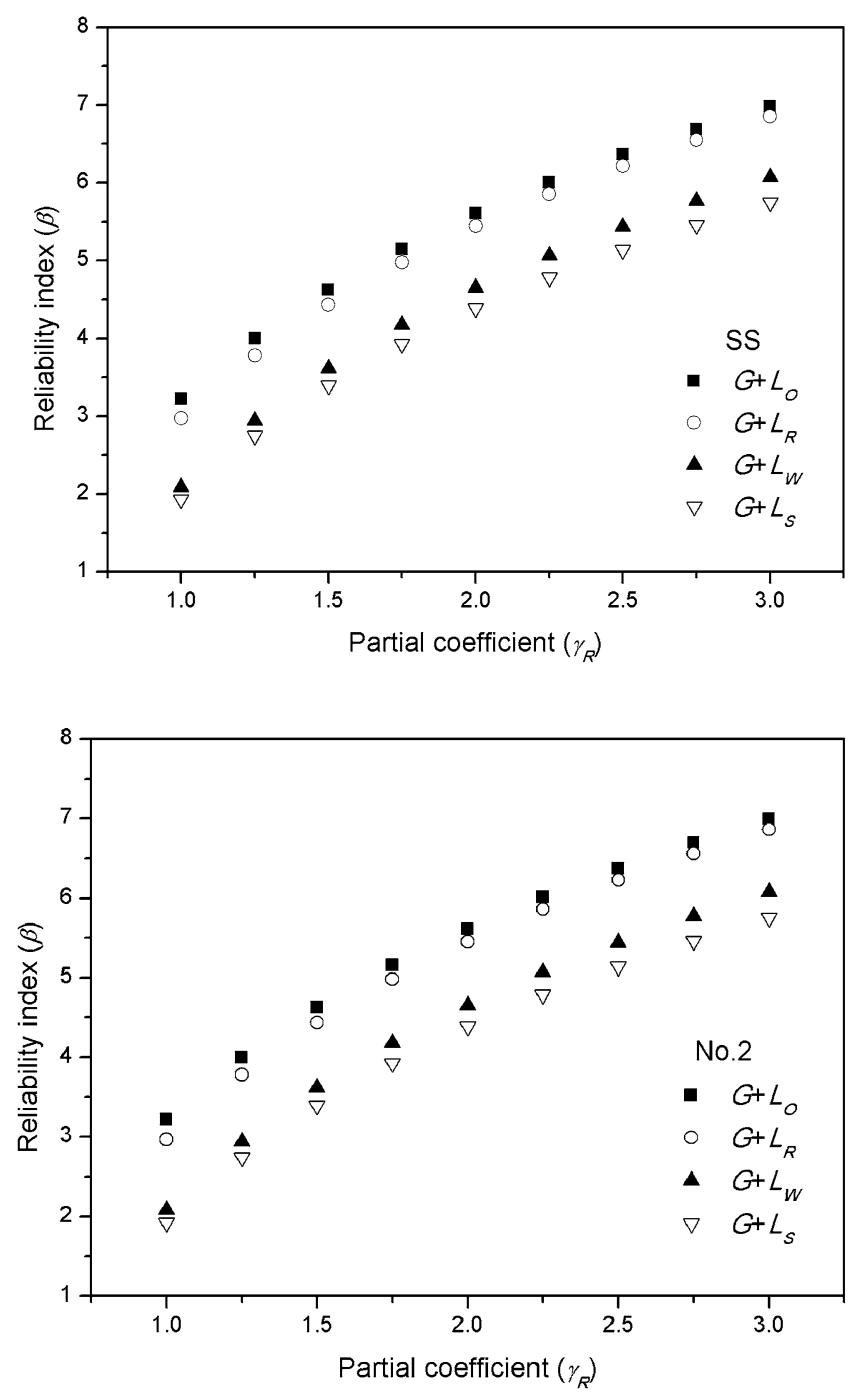

Fig. 3 Relationship between reliability index and partial coefficient

In addition, live-to-dead load ration is an important factor to determine the target reliability assessment. The reliability index $(\beta)$, which needs to meet the target index $\left(\beta_{0}=3.2\right)$, is used to determine the design value of $\mathrm{UCS}_{15}$. This is acquired by taking an average of the reliability index under the live-to-dead load ratio $(\rho)$, which is specified as $0.25,0.5,1.0,1.5,2.0,2.5,3.0,3.5$, and 4.0. Four load combinations, including $G+L_{O}, G+L_{R}$, $G+L_{W}$, and $G+L_{S}$, were used in the target reliability assessment.

Figure 2 showed that the relationship between reliability index $(\beta)$ and live-to-dead load ratio $(\rho)$ of each grade, under dead load $(G)$ plus live office load $\left(L_{O}\right)$. With the increase of $\rho$, the $\beta$ increased nonlinearly, but the increasing trend was gradually slowed down.

Meanwhile, the relationship between reliability index $(\beta)$ and resistance partial coefficient $\left(\gamma_{R}\right)$ for each grade, taking the average of all simulation load cases including
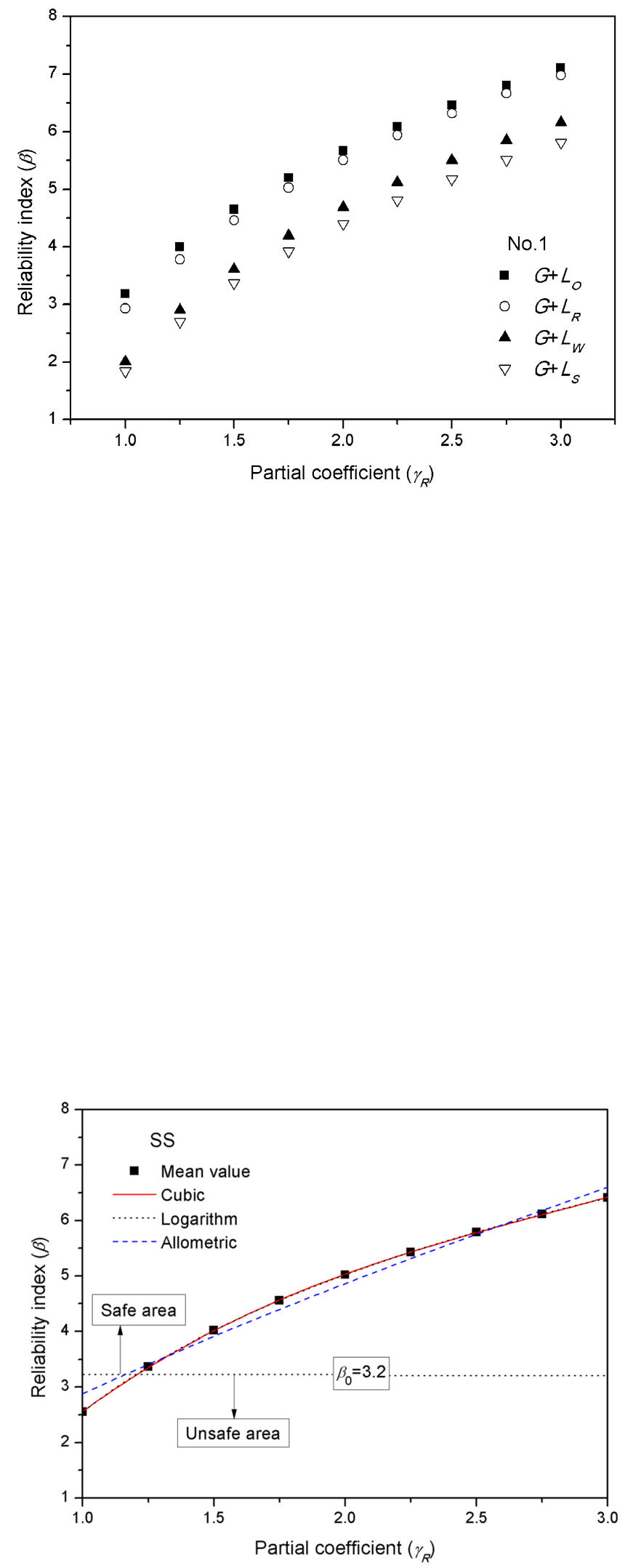

Fig. 4 Prediction of reliability index by partial coefficient for SS grade 
Table 8 Fitting results by various model

\begin{tabular}{|c|c|c|c|c|}
\hline Grade & Model & Calculation formula & $r^{2}$ & Std. error \\
\hline \multirow[t]{3}{*}{ SS } & Cubic & $y=0.215 x^{3}-1.828 x^{2}+6.450 x-2.275$ & 0.999 & 0.150 \\
\hline & Logarithm & $y=2.957+3.261 \ln (x-0.116)$ & 1000 & 0.015 \\
\hline & Allometric & $y=2.881 x^{0.754}$ & 0.981 & 0.101 \\
\hline \multirow[t]{3}{*}{ No. 1} & Cubic & $y=0.228 x^{3}-1.933 x^{2}+6.779 x-2.572$ & 0.999 & 0.163 \\
\hline & Logarithm & $y=2.937+3.383 \ln (x-0.123)$ & 1.000 & 0.021 \\
\hline & Allometric & $y=2.848 x^{0.781}$ & 0.979 & 0.108 \\
\hline \multirow[t]{3}{*}{ No. 2} & Cubic & $y=0.216 x^{3}-1.837 x^{2}+6.479 x-2.301$ & 0.999 & 0.151 \\
\hline & Logarithm & $y=2.955+3.271 \ln (x-0.117)$ & 1.000 & 0.016 \\
\hline & Allometric & $y=2.878 x^{0.757}$ & 0.981 & 0.101 \\
\hline
\end{tabular}

Std. error standard error

$G+L_{O}, G+L_{R}, G+L_{W}$, and $G+L_{S}$, is shown in Fig. 3. The reliability index increased with the resistance partial coefficient ranged from 1.0 to 3.0. Different load combinations have different reliability index. The maximum $\beta$ value was corresponding to dead load $(G)$ plus live office load $\left(L_{O}\right)$. The results obtained in this study are similar to those of previous researchers $[22,23]$.

To determine the resistance partial coefficient $\left(\gamma_{R}\right)$, the correlation between reliability index $(\beta)$ and resistance partial coefficient $\left(\gamma_{R}\right)$ fitted by cubic, logarithm, and allometric models for SS grade Chinese fir was shown in Fig. 4.

Table 8 indicated that the logarithm model could better fit the data than other models. The value of adjusted $r$ square is equal to 1.000 for each grade, respectively. Moreover,the stander error of logarithm model for each grade was the smallest. Therefore, logarithm model was selected to calculate the resistance partial coefficient $\left(\gamma_{R}\right)$.

To meet the reliability index $(\beta)$ of 3.2 , the resistance partial coefficients $\left(\gamma_{R}\right)$ were $1.187,1.204$, and 1.195 for SS, No. 1, and No. 2 grade, respectively. And the design values of compressive strength calculated by Eq. 10 were set to $13.751,13.186$, and $13.123 \mathrm{MPa}$ for SS, No. 1, and No. 2 grade, respectively.

\section{Conclusions}

The objective of this study was to determine the design value of compression strength parallel to grain for Chinese fir dimension lumber based on full-size testing. The results will provide fundamental parameters for the application of Chinese fir in the building structure field as a green building material. The conclusions are as follows:

1. The mean values of $\mathrm{UCS}_{15}$ for SS, No. 1, and No. 2 grade were $30.71,28.38$, and $29.37 \mathrm{MPa}$, respectively.

2. The results of reliability analysis indicated that reliability index increased nonlinearly with the live-to-dead ratio and resistance partial coefficient increased. The logarithm model fitted the data better than other models.

3. To meet the reliability index $(\beta=3.2)$, it was suggested that the design values of compressive strength were set to $13.751,13.18$, and $13.123 \mathrm{MPa}$ for SS, No. 1, and No. 2 grade, respectively.

Acknowledgements This work was supported by the Central PublicInterest Scientific Institution Basal Research Fund: (CAFYBB2016ZX002).

\section{References}

1. Xu JD (2014) The 8th forest resources inventory results and analysis in China. Forest Econ 3:6-8

2. Xu CD (2014) Forest management in China from data of eight forest resources inventories. Forest Econ 4:8-11

3. Ren HQ, Huang AM, Liu QL, Fei BH (2006) Research on and suggestions for processing and utilization of Chinese fir. China Wood Ind 20:25-27

4. Ren HQ, Guo W, Fei BH, Huang ZH, Luo XQ (2010) Mechanical stress grading of Chinese fir dimension lumber for light wood structure houses. J Build Mater 13:363-366

5. Long C (2007) Comparative study on the influence of various testing methods on the mechanical properties of Chinese fir plantation dimension lumber. Chinese Academy of Forestry, Beijing

6. Yuan D, Wang XH, Fei BH, Du M (2011) Status and advantage analysis of developing modern wood construction in China. Forest Econ 10:61-64

7. National Lumber Grades Authority (NLGA) (2005) NLGA standard grading rules for Canadian lumber. National Lumber Grades Authority (NLGA), Burnaby

8. Chinese Nation Standard GB 50005-2003 (2003) Code for design of timber structures. Standardization Administration of China, Beijing

9. Zhuang XJ (2004) Reliability study of North American dimension lumber in the Chinese timber structures design code. University of British Columbia, Vancouver

10. Zhong Y, Jiang ZH, Ren HQ (2015) Reliability analysis of compression strength of dimension lumber of Northeast China Larch. Constr Build Mater 84:12-18 
11. Zhou HB, Ren HQ, Lv JX, Jiang JH, Wang XS (2010) Size effect of length on tensile strength of visually-graded Chinese fir dimension lumber. J Build Mater 13:646-649

12. Guo W, Ren HQ, Fei BH, Lu JX (2011) Mechanical properties of three grades of Chinese fir dimension lumber. Sci Silv Sin 47:139-143

13. ASTM D1990-07 (2007) Standard practice for establishing allowable properties for visually-graded dimension lumber from in-grade tests of full-size specimens. American Society for Testing and Materials, Philadelphia

14. ASTM D4761-09 (2009) Standard test methods for mechanical properties of lumber and wood-base structural material. American Society for Testing and Materials, Philadelphia

15. Kolmogorov A (1932) Sulla determinazione emppirica di una legge di distribuzione. Ist Ital Attuar 4(1):83-91

16. Guo W (2007) Study on the applicability of North America visual grading rules for dimension lumber of Chinese fir plantation. Chinese Academy of Forestry, Beijing

17. Long C, Lv JX (2007) Progress on the testing methods for mechanical properties of dimensional lumber. China Wood Ind $21: 1-4$
18. Green DW, Rosales AN (2006) Properties and grading of Danto and Ramon 2 by 4's. Forest Prod J 56:19-25

19. Chinese Nation Standard GB50068-2001 (2001) Unified standard for reliability design of building structures. Standardization Administration of China, Beijing

20. ASTM D2915-10 (2010) Standard practice for evaluating allowable properties for grades of structural lumber. American Society for Testing and Materials, Philadelphia

21. Chinese Nation Standard GB50009-2012 (2012) Load code for the design of building structures. Standardization Administration of China, Beijing

22. Li TE (2011) Determining the strength design values of wood based on the reliability requirements. Harbin Institute of Technology, Haerbin

23. Zhong Y, Ren HQ (2014) Reliability analysis for the bending strength of larch $2 \times 4$ lumber. BioRes 9:6914-6923 